\title{
An outcome-based definition of low birthweight for births in low- and middle- income countries: a secondary analysis of the WHO global survey on maternal and perinatal health
}

Malinee Laopaiboon ${ }^{1}$, Pisake Lumbiganon ${ }^{2 *}$ (D), Siwanon Rattanakanokchai ${ }^{1}$, Warut Chaiwong ${ }^{3}$, João Paulo Souza ${ }^{4}$, Joshua P. Vogel ${ }^{5,6}$, Rintaro Mori ${ }^{7}$ and Ahmet Metin Gülmezoglu ${ }^{8}$

\begin{abstract}
Background: $2500 \mathrm{~g}$ has been used worldwide as the definition of low birthweight (LBW) for almost a century. While previous studies have used statistical approaches to define LBW cutoffs, a LBW definition using an outcomebased approach has not been evaluated. We aimed to identify an outcome-based definition of LBW for live births in low- and middle-income countries (LMICS), using data from a WHO cross-sectional survey on maternal and perinatal health outcomes in 23 countries.

Methods: We performed a secondary analysis of all singleton live births in the WHO Global Survey (WHOGS) on Maternal and Perinatal Health, conducted in African and Latin American countries (2004-2005) and Asian countries (2007-2008). We used a two-level logistic regression model to assess the risk of early neonatal mortality (ENM) associated with subgroups of birthweight $(<1500 \mathrm{~g}, 1500-2499 \mathrm{~g}$ with $100 \mathrm{~g}$ intervals; 2500-3499 $\mathrm{g}$ as the reference group). The model adjusted for potential confounders, including maternal complications, gestational age at birth, mode of birth, fetal presentation and facility capacity index (FCl) score. We presented adjusted odds ratios (aORs) with $95 \%$ confidence intervals (Cls). A lower Cl limit of at least two was used to define a clinically important definition of LBW.

Results: We included 205,648 singleton live births at 344 facilities in 23 LMICs. An aOR of at least 2.0 for the ENM outcome was observed at birthweights below $2200 \mathrm{~g}$ (aOR 3.8 (95\% Cl; 2.7, 5.5) of 2100-2199 g) for the total population. For Africa, Asia and Latin America, the $95 \% \mathrm{Cl}$ lower limit aORs of at least 2.0 were observed when birthweight was lower than $2200 \mathrm{~g}(\mathrm{aOR} 3.6$ (95\% Cl; 2.0, 6.5) of 2100-2199 g), $2100 \mathrm{~g}$ (aOR 7.4 (95\% Cl; 5.1, 10.7) of $2000-2099 \mathrm{~g})$ and $2200 \mathrm{~g}(\mathrm{aOR} 6.1(95 \% \mathrm{Cl} ; 3.4,10.9)$ of $2100-2199 \mathrm{~g})$ respectively.

Conclusion: A birthweight of less than $2200 \mathrm{~g}$ may be an outcome-based threshold for LBW in LMICs. Regionalspecific thresholds of low birthweight ( $<2200 \mathrm{~g}$ in Africa, $<2100 \mathrm{~g}$ in Asia and $<2200 \mathrm{~g}$ in Latin America) may also be warranted.
\end{abstract}

Keywords: Low birthweight, Outcome-based definition, Early neonatal mortality

\footnotetext{
* Correspondence: pisake@kku.ac.th; lumbiganon.pisake@gmail.com

${ }^{2}$ Department of Obstetrics and Gynaecology, Faculty of Medicine, Khon Kaen

University, Khon Kaen, Thailand

Full list of author information is available at the end of the article
}

(c) The Author(s). 2019 Open Access This article is distributed under the terms of the Creative Commons Attribution 4.0 International License (http://creativecommons.org/licenses/by/4.0/), which permits unrestricted use, distribution, and reproduction in any medium, provided you give appropriate credit to the original author(s) and the source, provide a link to the Creative Commons license, and indicate if changes were made. The Creative Commons Public Domain Dedication waiver (http://creativecommons.org/publicdomain/zero/1.0/) applies to the data made available in this article, unless otherwise stated. 


\section{Background}

The term low birthweight (LBW) is defined by the World Health Organization (WHO) as the weight at birth of a neonate less than $2500 \mathrm{~g}(\mathrm{~g})$, a cut-off that is often consistent with 10th percentile for gestation $[1,2]$. This cut-off was based on epidemiological observations that neonates of birthweight less than $2500 \mathrm{~g}$ were more likely to die than heavier newborns [3], with mortality rates rising rapidly as birthweight decreases [4-6]. WHO advises that the $2500 \mathrm{~g}$ cut-off value should be used for international health statistics comparisons [1].

Low birthweight is an important public health indicator of maternal malnutrition and health, and poor antenatal care [1, 3]. Globally, more than 20 million newborns (an estimated 15.5\% of all births) are born low birthweight each year. More than 95\% of these LBW neonates are born in low- and middle-income countries (LMICs) [1]. There is significant variation of LBW rates among geographical regions. The highest LBW rates are seen in Asia (18.3\%), about three times higher than the lowest rate, in Europe (6.4\%). There is considerable variation between sub-regions in Asia, ranging from 5.9\% in Eastern Asia to 27\% in South-central Asia [1, 7].

LBW has been associated with increased risks of neonatal mortality and several neonatal morbidities, including birth asphyxia, acute respiratory infections and diarrhea disease, as well as longer-term adverse health outcomes such as neurological disorders, impaired language development, poor academic performance, cardiovascular disease and diabetes [3, 8, 9]. Decreasing the global burden of LBW could substantially reduce costs to families and o healthcare systems in LMICs [10].

However, some evidence has emerged that the cut-off value of $2500 \mathrm{~g}$ to define LBW may not be appropriate for all settings. For example, some countries such as Sri Lanka have a high prevalence of neonates with birthweight less than $2500 \mathrm{~g}$ do not have correspondingly high neonatal mortality rates [11]. To this effect, WHO suggested that individual countries should adopt a population-specific cut-off value for LBW to guide clinical care [1]. However, in practice a birthweight below $2500 \mathrm{~g}$ is still in routine use in most LMICs.

Defining an appropriate LBW cut-off is challenging. If too low, some neonates may not get necessary care. Alternatively, if the value is too high, some neonates may get additional care that is not necessary. In many LMICs, inappropriate use of limited health resources can disadvantage neonates requiring more intensive care. Therefore, further investigation of the most appropriate cut-off for LBW remains an important issue.

Previous studies have defined population-specific cutoffs for LBW in high-income countries (HICs) [12, 13] and LMICs [14, 15]. This is typically done using statistical methods, where the lowest 10th percentile of the birthweight distribution is used as the cut-off for LBW. These has often resulted in LBW cut-offs higher than $2500 \mathrm{~g}$ - for example, $2750 \mathrm{~g}$ in the US in 1992 [12] to $3000 \mathrm{~g}$ in Denmark in 2007 [13]. Recent studies in LMICs have also identified alternative LBW cut-offs, such as $2600 \mathrm{~g}$ in a study in sub-urban Cameroon [14] and $2700 \mathrm{~g}$ in a rural community [15] in Cameroon.

Previous studies have used an outcome-based approach for identification of cut-off weights for fetal growth [16] and macrosomia [17]. By using the Health Statistics database for the years 1995-2002 of the United State National Center, Joseph et al. generated fetal growth standards for singleton and twin neonates based on severe morbidity and mortality outcomes [16]. In a secondary analysis of the database of the World Health Organization (WHO) Global Survey on Maternal and Perinatal Health (2004-2008) conducted in 23 LMICs in Africa, Asia, and Latin America, Ye et al. defined macrosomia based on the adjusted assoiated risk of birthweight for maternal and perinatal mortality and morbidity in term pregnancies [17]. However, we have identified no previous analyses that have defined a LBW cut-off value using an outcome-based approach. This study therefore aimed to identify an outcome-based definition of LBW for LMICs using the WHO Global Survey database.

\section{Methods}

\section{Study design and population}

We conducted a secondary analysis using data from the WHO Global Survey (WHOGS) on Maternal and Perinatal Health conducted in Africa, Asia and Latin America. The WHOGS was a prospective, facility-based, crosssectional survey on maternal and perinatal health interventions and outcomes. The primary aim of the survey was to assess the association between mode of birth and maternal and perinatal health outcomes $[18,19]$. Details of the survey have been reported elsewhere [18-20]. A total of 373 facilities in 24 countries in three regions participated in this survey. Data collection was performed in 2004-05 for Africa and Latin America, and in 2007-08 for Asia. Trained data collectors reviewed medical records of individual women from the time of attending participating facilities for delivery until discharge, death or day 7 postpartum. Data were abstracted from medical records into structured case record forms. The period of data collection was two months in facilities with at least 6000 deliveries per year and three months in facilities with less than 6000 deliveries per year. Institutional data were collected for each participating facility, including information on available resources for obstetric care. The data was obtained through an interview with the hospital director or head of obstetrics, and data entered into the pre-specified institutional form. 


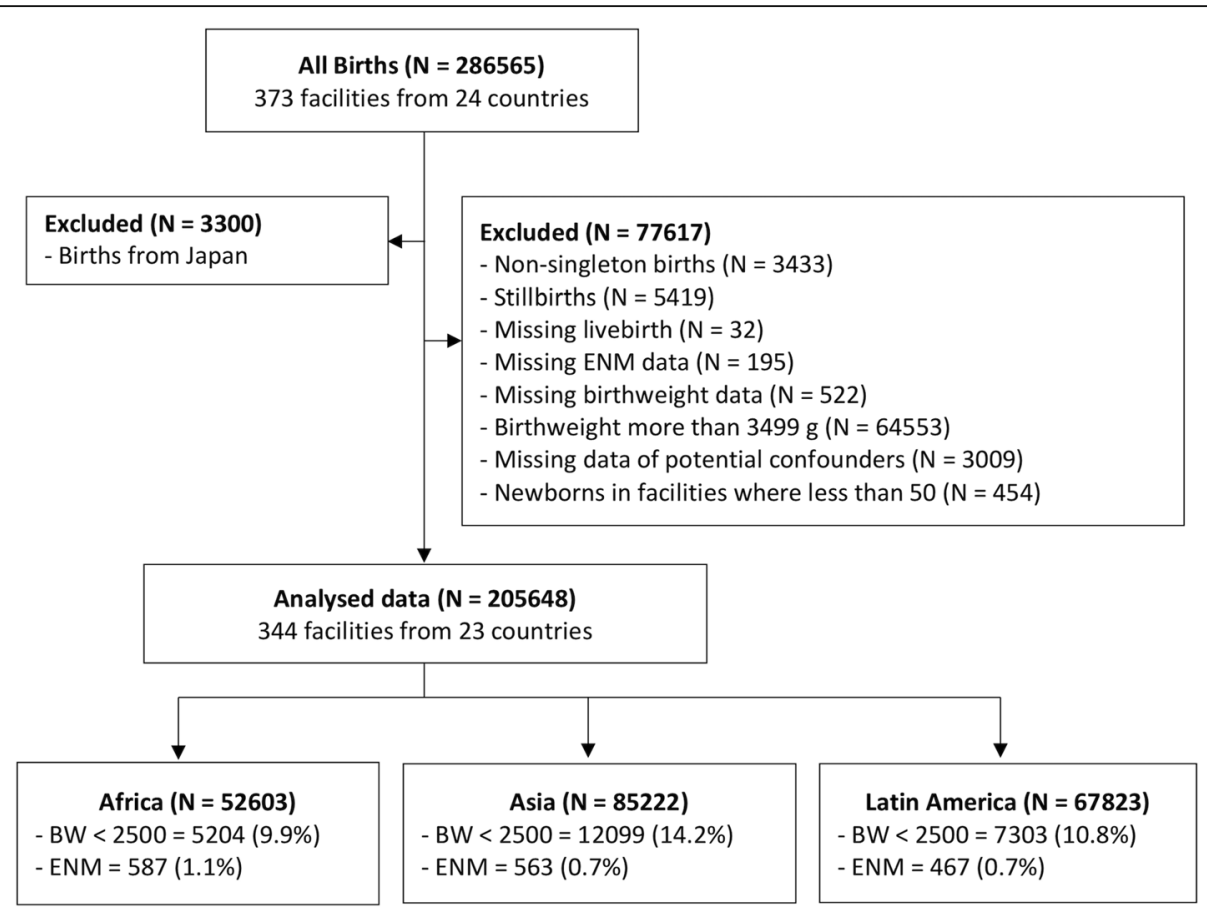

Fig. 1 Flow chart of inclusion and exclusion of study neonates

The WHOGS protocol was approved by the WHO ethics review committee and the relevant local review committees for all participating centres [19]. Individual informed consent was not obtained; survey data were extracted from medical records without individual identification or patient contact [19]. We received permission to use this data from the Department of Reproductive Health and Research, WHO on January 14th, 2014.

Our analysis was restricted to singleton, live newborns in participating facilities in low- and middle-income countries (facilities and newborns in Japan were excluded). We aimed to evaluate associations between birthweight cut- offs and early neonatal mortality (ENM) . ENM was defined as death occurring in hospital prior to discharge or Day 7 (whichever came first). We adjusted for potential confounders, including maternal complications (such as chronic hypertension, sickle cell anaemia) gestational age at birth, mode of birth and fetal presentation at birth. Newborns with missing information on birthweight, ENM outcome and potential confounders were excluded. We also excluded facilities that had less than 50 newborns [21]. The selection process for the analysis population is shown in Fig. 1.

We used data on the availability of basic and essential maternal healthcare services of individual participating facilities as potential confounding factors at facility level. Facilities were classified into different levels, using the existing WHOGS facility capacity index (FCI) score [18]. FCI scores ranged between 0 and 16. Facilities with a total score of 9 or less were defined as low capacity, those with scores of between 10 and 12 as medium capacity, and those with scores of 13 or more as high capacity [18].

\section{Statistical analysis}

We assessed the association of birthweight groups with ENM using two-level logistic regression models. We assigned facilities to represent units at level two and individuals within facilities at level one. We used the birthweight range of $2500-3499 \mathrm{~g}$ as the reference group based on the current global clinical practice for normal neonatal birthweight range. In addition, the rates of ENM at $100 \mathrm{~g}$ intervals within $2500-3499 \mathrm{~g}$ were quite similar (around $0.5 \%$ in our database) [see Additional file 1]. We classified birthweights of $1500-2499 \mathrm{~g}$ into $100 \mathrm{~g}$ intervals. Birthweights less than $1500 \mathrm{~g}$ were classified into one group. We adjusted for potential confounders at both levels in the models (see above). We estimated adjusted odds ratios (ORs) and 95\% confidence intervals (CIs) of ENM by absolute birthweight subgroups. We analysed all associations in the whole database and by region (Africa, Asia and Latin America).

It is well-known that the risk of adverse neonatal outcomes increases as birthweight decreases; very low birthweight infants ( $1500 \mathrm{~g}$ or less) are at greatest risk [2225]. We applied this concept in our analysis to identify an appropriate low birthweight cut-off based on the ENM. We used an a priori odds ratio threshold of 2.0 
Table 1 Country-specific birthweight and early neonatal mortality distribution of singleton liveborn births

\begin{tabular}{|c|c|c|c|c|c|c|c|}
\hline \multirow[t]{2}{*}{ Countries } & \multirow{2}{*}{$\begin{array}{l}\text { Number } \\
\text { of } \\
\text { facilities }\end{array}$} & \multirow{2}{*}{$\begin{array}{l}\text { Number } \\
\text { of } \\
\text { newborns }\end{array}$} & \multicolumn{4}{|c|}{ Birthweight (g) } & \multirow{2}{*}{$\begin{array}{l}\text { Early } \\
\text { Neonatal } \\
\text { Mortality } \\
(\%)\end{array}$} \\
\hline & & & Mean & (SD) & $<1500(\%)$ & $<2500(\%)$ & \\
\hline Total & 344 & 205,648 & 2902 & (413) & 1.0 & 12.0 & 0.8 \\
\hline Africa & 118 & 52,603 & 2935 & (389) & 0.8 & 9.9 & 1.1 \\
\hline Algeria & 18 & 7516 & 3025 & (390) & 1.0 & 7.4 & 1.3 \\
\hline Angola & 15 & 3920 & 2903 & $(405)$ & 1.2 & 11.8 & 0.5 \\
\hline Congo & 21 & 6767 & 2874 & (392) & 0.6 & 14.4 & 1.0 \\
\hline Kenya & 20 & 13,586 & 2921 & (395) & 1.0 & 9.7 & 1.8 \\
\hline Niger & 11 & 6526 & 2906 & (381) & 0.5 & 11.6 & 0.4 \\
\hline Nigeria & 21 & 5704 & 2932 & (380) & 0.9 & 8.2 & 0.8 \\
\hline Uganda & 12 & 8584 & 2964 & (363) & 0.6 & 7.7 & 1.1 \\
\hline Asia & 112 & 85,222 & 2838 & $(406)$ & 0.8 & 14.2 & 0.7 \\
\hline Cambodia & 5 & 4457 & 2897 & (383) & 0.8 & 9.3 & 1.1 \\
\hline China & 21 & 9357 & 3045 & (332) & 0.4 & 5.5 & 0.3 \\
\hline India & 20 & 22,008 & 2653 & (405) & 1.2 & 22.1 & 1.1 \\
\hline Nepal & 8 & 6852 & 2786 & (386) & 0.5 & 13.7 & 0.9 \\
\hline Philippines & 17 & 11,732 & 2819 & (419) & 1.3 & 16.2 & 1.1 \\
\hline Sri Lanka & 14 & 13,191 & 2846 & (381) & 0.6 & 15.5 & 0.2 \\
\hline Thailand & 12 & 8068 & 2939 & (380) & 0.7 & 10.8 & 0.4 \\
\hline Viet Nam & 15 & 9557 & 2997 & (335) & 0.3 & 5.7 & 0.1 \\
\hline Latin America & 114 & 67,823 & 2958 & (428) & 1.4 & 10.8 & 0.7 \\
\hline Argentina & 14 & 6661 & 2975 & (453) & 1.9 & 11.0 & 0.5 \\
\hline Brazil & 19 & 10,955 & 2956 & (437) & 1.5 & 11.6 & 0.8 \\
\hline Cuba & 17 & 8300 & 3013 & (379) & 0.7 & 8.0 & 0.2 \\
\hline Ecuador & 14 & 9666 & 2898 & (432) & 1.5 & 12.4 & 0.7 \\
\hline Mexico & 21 & 15,716 & 2932 & (429) & 1.5 & 11.6 & 0.6 \\
\hline Nicaragua & 6 & 4271 & 2946 & (384) & 0.7 & 9.5 & 1.0 \\
\hline Paraguay & 6 & 2001 & 2990 & $(442)$ & 1.6 & 10.4 & 1.1 \\
\hline Peru & 17 & 10,253 & 2997 & (438) & 1.7 & 9.8 & 1.0 \\
\hline
\end{tabular}

(for the lower confidence interval) as a criterion for clinical significance, as per previous studies [17, 26, 27]. Thus, in this analysis the clinical significance was defined as when the lower limit of the 95\% confidence interval for the adjusted OR was at least 2.0 [28]. We, therefore, defined LBW from the lowest birthweight of the subgroup that its lower subgroups had lower limit of the $95 \%$ confidence interval for adjusted OR was at least 2.0 [28].

The descriptive analyses were also done using $\mathrm{R}$ software. We used package lme4 of $\mathrm{R}$ software to analyse the two-level logistic regression model [29].

\section{Results}

A total of 205,648 singleton live newborns at 344 facilities in 23 LMICs were included in this analysis (Fig. 1). There were differences in the birthweight distribution for the three regions. Mean birthweights were $2935 \mathrm{~g}$ (SD $389 \mathrm{~g}$ ) in Africa, $2838 \mathrm{~g}$ (SD $406 \mathrm{~g}$ ) in Asia and 2958 g (SD $428 \mathrm{~g}$ ) in Latin America. The rates of birthweight $<2500 \mathrm{~g}$ were 9.9, 14.2 and $10.8 \%$, in Africa, Asia and Latin America respectively. The rates of birthweight < $1500 \mathrm{~g}$ were $0.8,0.8$ and $1.4 \%$, in Africa, Asia and Latin America respectively. Wide variation of birthweight was observed between Asian countries (Table 1).

We present the associations between birthweight intervals and potential confounding factors in Table 2 . Mean gestational age was positively associated with birthweight. Higher rates of all potential confounding factors were seen among infants with lower birthweights. In the study population, the caesarean section rate was 24.3 and $16.9 \%$ of women had a maternal complication.

ENM rates were 1.1, 0.7 and $0.7 \%$ in Africa, Asia and Latin America respectively. When compared to the 
Table 2 Distribution of individual potential confounding factors by birthweight

\begin{tabular}{|c|c|c|c|c|c|c|}
\hline \multirow{2}{*}{$\begin{array}{l}\text { Birthweight } \\
\text { (g) }\end{array}$} & \multirow[t]{2}{*}{$n$} & \multicolumn{2}{|c|}{ Gestational age } & \multirow{2}{*}{$\begin{array}{l}\text { Cesarean section } \\
(\%)\end{array}$} & \multirow{2}{*}{$\begin{array}{l}\text { Breech presentation at birth } \\
(\%)\end{array}$} & \multirow{2}{*}{$\begin{array}{l}\text { Maternal complications }{ }^{\mathrm{a}} \\
(\%)\end{array}$} \\
\hline & & Mean & (SD) & & & \\
\hline Overall & 205,648 & 38.5 & (2.0) & $49,964(24.3)$ & $9099(4.4)$ & $34,642(16.9)$ \\
\hline$<1500$ & 2072 & 30.6 & (4.1) & 38.9 & 18.6 & 25.3 \\
\hline 1500-1599 & 602 & 33.1 & (3.2) & 32.4 & 11.1 & 20.3 \\
\hline 1600-1699 & 521 & 33.7 & (3.1) & 39.3 & 12.1 & 22.5 \\
\hline 1700-1799 & 811 & 34.4 & (3.0) & 35.8 & 12.1 & 20.3 \\
\hline 1800-1899 & 973 & 34.6 & (2.9) & 35.9 & 10.4 & 22.1 \\
\hline 1900-1999 & 1032 & 35.2 & (2.9) & 36.7 & 9.5 & 23.3 \\
\hline 2000-2099 & 2807 & 36.7 & (2.6) & 26.7 & 7.5 & 15.7 \\
\hline 2100-2199 & 2165 & 36.9 & (2.5) & 29.7 & 7.3 & 19.2 \\
\hline $2200-2299$ & 3817 & 37.2 & (2.3) & 26.2 & 6.4 & 15.6 \\
\hline 2300-2399 & 4178 & 37.6 & (2.0) & 25.5 & 5.2 & 18.2 \\
\hline $2400-2499$ & 5628 & 37.9 & (2.0) & 25.9 & 5.5 & 18.7 \\
\hline 2500-3499 & 181,042 & 38.8 & (1.6) & 23.7 & 3.9 & 16.6 \\
\hline
\end{tabular}

All variables differed significantly by birthweight categories ( $p$-value $<0.001$ )

${ }^{a}$ Maternal complications included chronic hypertension, cardiac disease, renal disease, chronic respiratory condition, diabetes mellitus, malaria, sickle cell anaemia, severe anaemia, pyelonephritis or urinary infection, HIV/AIDS, Thalassemia and other medical conditions

reference (normal birthweight) group (2500-3499 g), adjusted ORs of ENM show statistical significance when birthweight was lower than $2500 \mathrm{~g}$ in the total population and each region. However, adjusted ORs of ENM in birthweights of 2300-2399 g in Africa (aOR 1.7 (95\% CI; 0.9, 3.3)) and Asia (aOR 1.3 (95\% CI; 0.6, 2.7)) did not reach statistical significance.

The adjusted ORs of ENM were similar (about 2.0) for birthweight intervals 2400-2499 g and 2200-2299 g, compared to the reference group. The adjusted ORs gradually increased from 3.8 (95\% CI; $2.7,5.5)$ for birthweights of $2100-2199 \mathrm{~g}$ to 17.9 (95\% CI; 13.3, 24.1) in birthweights of $1500-1599 \mathrm{~g}$ (Fig. 2). The adjusted OR increased up to 32.0 (95\% CI; 25.6, 40.0) in birthweight $<1500 \mathrm{~g}$ (Table 3). Based on the predefined clinical significance criterion for aOR (lower limit of $95 \% \mathrm{CI}$ of 2.0), the LBW cut-off was $2200 \mathrm{~g}$ for the total population.

When compared to the reference group (2500-3499 g), the adjusted ORs of ENM in birthweight of $<2500 \mathrm{~g}$ were high across all three regions, similar to the total population. However, the adjusted ORs of ENM in birthweight of $<1500 \mathrm{~g}$ in Asia reached 54.3 (95\% CI; 37.4, 78.9) while those in Africa and Latin America was 30.4 (95\% CI; 21.1, 43.7) and 18.1 (95\% CI; 11.5, 28.5), respectively (Table 4).

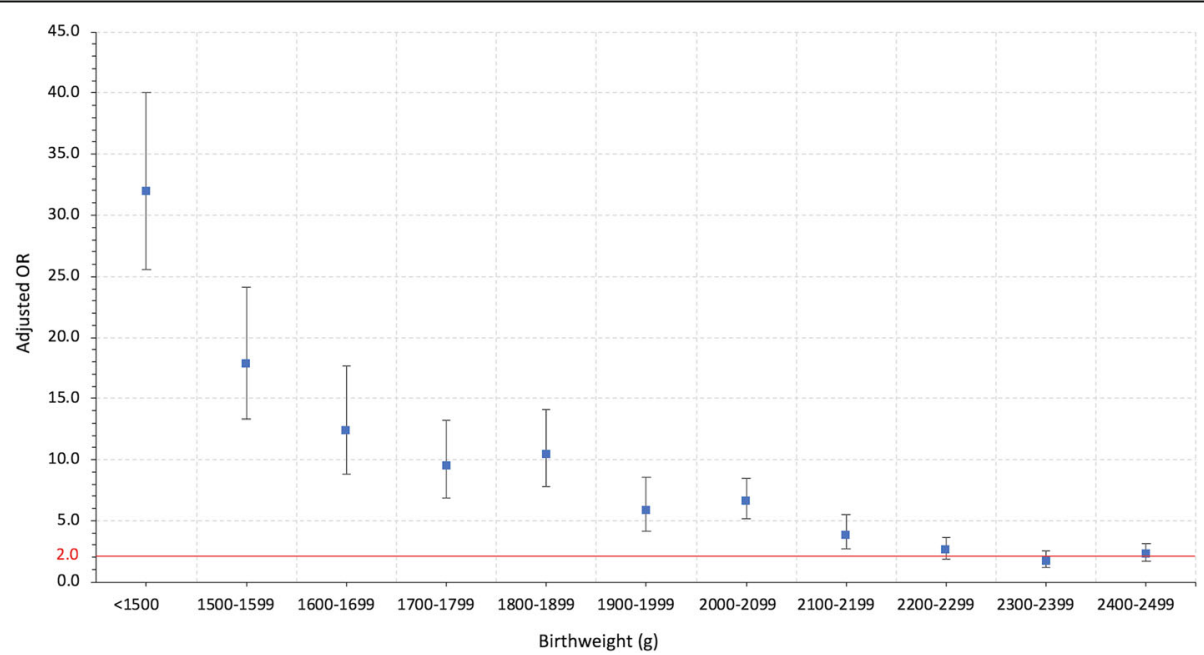

Fig. 2 Adjusted odds ratios with $95 \% \mathrm{Cl}$ of early neonatal mortality by birthweight in the total population. Solid red line shows the adjusted OR 2.0 for clinical significance 
Table 3 Rate and adjusted odds ratios of early neonatal mortality by birthweight

\begin{tabular}{llll}
\hline $\begin{array}{l}\text { Birthweight } \\
\text { g })\end{array}$ & $n$ & \multicolumn{2}{l}{ Early Neonatal Mortality } \\
\cline { 3 - 4 } & & Rate $(\%)$ & Adjusted OR $(95 \%$ Cl) \\
\hline$<1500$ & 2072 & 29.0 & $32.0(25.6,40.0)$ \\
$1500-1599$ & 602 & 13.8 & $17.9(13.3,24.1)$ \\
$1600-1699$ & 521 & 9.6 & $12.5(8.8,17.7)$ \\
$1700-1799$ & 811 & 6.2 & $9.5(6.8,13.2)$ \\
$1800-1899$ & 973 & 6.8 & $10.5(7.8,14.1)$ \\
$1900-1999$ & 1032 & 3.6 & $5.9(4.1,8.5)$ \\
$2000-2099$ & 2807 & 3.1 & $6.6(5.2,8.5)$ \\
$2100-2199$ & 2165 & 1.6 & $3.8(2.7,5.5)$ \\
$2200-2299$ & 3817 & 1.0 & $2.6(1.9,3.7)$ \\
$2300-2399$ & 4178 & 0.6 & $1.7(1.1,2.6)$ \\
$2400-2499$ & 5628 & 0.7 & $2.3(1.7,3.1)$ \\
$2500-3499$ & 181,042 & 0.3 & 1.0 \\
\hline
\end{tabular}

Adjusted for gestational age, mode of delivery, fetal presentation at delivery, maternal complications and complexity index

${ }^{\mathrm{a}} R O C=0.9118$

With regards to the pre-defined clinical significance criterion, in Africa the adjusted OR was 3.6 (95\% CI; $2.0,6.5$ ) in birthweights of $2100-2199$ g. In Asia, the adjusted OR was $7.4(95 \% \mathrm{CI} ; 5.1,10.7)$ in birthweights of $2000-2099 \mathrm{~g}$. In Latin America, the adjusted OR was $6.1(95 \% \mathrm{CI}$; 3.4, 10.9) in birthweights of $2100-2199 \mathrm{~g}$. Therefore, the LBW cut-offs were $2200 \mathrm{~g}, 2100 \mathrm{~g}$ and $2200 \mathrm{~g}$ for Africa, Asia and Latin America respectively (Fig. 3).

\section{Discussion}

Our findings show that a low birthweight cut-off based on ENM outcome is $2200 \mathrm{~g}$ for a large, multi-country population of live singleton newborns. The low birthweight cut-off at regional level were similar, $2200 \mathrm{~g}$, $2100 \mathrm{~g}$ and $2200 \mathrm{~g}$ for Africa, Asia and Latin America respectively. These LBW cut-offs are lower than the traditional criterion of $2500 \mathrm{~g}$. The risks of ENM were quite similar among newborns in with birthweight ranges of 2200-2299 g, 2300-2399 g and 2400-2499g with adjusted ORs around two, but their lower limit of the 95\% confidence intervals did not reach our pre-specified criterion for clinical significance.

Although the a priori adjusted OR of 2.0 for ENM was arbitrarily set as clinically important, the value has been used in previous studies. Ye et al. [17] used the OR of 2.0 to define macrosomia that is clinically significant risk for maternal and perinatal mortality and morbidity in LMICs, also using the WHOGS database. Boulet et al. [27] also used this value for defining clinically important fetal growth restriction. Barrette et al. [26] used the inverse value of 2.0 relative risk (0.5) to clinically justify difference between the planned caesarean delivery and vaginal delivery in the randomized trial of the Twin Birth Study Collaborative Group. However, previous studies $[17,26,27]$ did not report whether the clinically significant OR of 2.0 was identified with respect to the lower 95\% confidence interval. This concept has been suggested by Mccluskey [28] in which clinical significance of any data has to be above or below the range of confidence interval that shows statistical significance. We

Table 4 Rate and adjusted odds ratios of early neonatal mortality by birthweight and regions

\begin{tabular}{|c|c|c|c|c|c|c|c|c|c|}
\hline \multirow{3}{*}{$\begin{array}{l}\text { Birthweight } \\
\text { (g) }\end{array}$} & \multicolumn{9}{|c|}{ Early neonatal mortality } \\
\hline & \multicolumn{3}{|c|}{ Africa $^{a}(n=52,603)$} & \multicolumn{3}{|c|}{$\operatorname{Asia}^{\mathrm{b}}(n=85,222)$} & \multicolumn{3}{|c|}{ Latin America $^{c}(n=67,823)$} \\
\hline & $\bar{n}$ & Rate (\%) & Adjusted OR (95\% Cl) & $\mathrm{n}$ & Rate (\%) & Adjusted OR (95\% Cl) & $n$ & Rate (\%) & Adjusted OR $(95 \% \mathrm{Cl})$ \\
\hline$<1500$ & 435 & 36.8 & $30.4(21.1,43.7)$ & 677 & 28.5 & $54.3(37.4,78.9)$ & 960 & 25.8 & $18.1(11.5,28.5)$ \\
\hline 1500-1599 & 114 & 22.8 & $20.6(11.9,35.7)$ & 327 & 11.9 & $23.1(14.9,36.0)$ & 161 & 11.2 & $13.9(7.5,25.5)$ \\
\hline 1600-1699 & 116 & 14.7 & $11.0(6.0,20.4)$ & 209 & 7.7 & $15.6(8.5,28.5)$ & 196 & 8.7 & $12.4(6.8,22.8)$ \\
\hline 1700-1799 & 143 & 7.7 & $6.4(3.2,12.7)$ & 387 & 5.9 & $13.4(8.2,22.0)$ & 281 & 5.7 & $8.8(4.8,16.1)$ \\
\hline 1800-1899 & 175 & 12.6 & $11.5(6.8,19.5)$ & 458 & 7.0 & $16.3(10.6,25.2)$ & 340 & 3.5 & $5.2(2.7,10.3)$ \\
\hline 1900-1999 & 228 & 6.6 & $6.5(3.7,11.6)$ & 431 & 2.8 & $7.4(3.9,13.9)$ & 373 & 2.7 & $4.4(2.2,9.0)$ \\
\hline 2000-2099 & 636 & 4.1 & $5.5(3.6,8.6)$ & 1571 & 2.7 & $7.4(5.1,10.7)$ & 600 & 3.2 & $8.3(4.8,14.3)$ \\
\hline 2100-2199 & 481 & 2.7 & $3.6(2.0,6.5)$ & 999 & 0.8 & $2.7(1.3,5.6)$ & 685 & 2.0 & $6.1(3.4,10.9)$ \\
\hline 2200-2299 & 682 & 2.2 & $3.0(1.8,5.2)$ & 2225 & 0.7 & $2.3(1.4,4.0)$ & 910 & 0.9 & $3.0(1.4,6.3)$ \\
\hline 2300-2399 & 901 & 1.1 & $1.7(0.9,3.3)$ & 2043 & 0.3 & $1.3(0.6,2.7)$ & 1234 & 0.6 & $2.6(1.3,5.5)$ \\
\hline 2400-2499 & 1293 & 1.3 & $2.2(1.3,3.6)$ & 2772 & 0.5 & $2.2(1.3,3.7)$ & 1563 & 0.6 & $3.0(1.5,5.8)$ \\
\hline 2500-3499 & 47,399 & 0.5 & 1.0 & 73,123 & 0.2 & 1.0 & 60,520 & 0.1 & 1.0 \\
\hline
\end{tabular}

Adjusted for gestational age, mode of delivery, fetal presentation at delivery, maternal complications and complexity index

${ }^{\mathrm{a}} \mathrm{ROC}=0.8804$

${ }^{\mathrm{b}} \mathrm{ROC}=0.9101$

${ }^{c} R O C=0.9245$ 

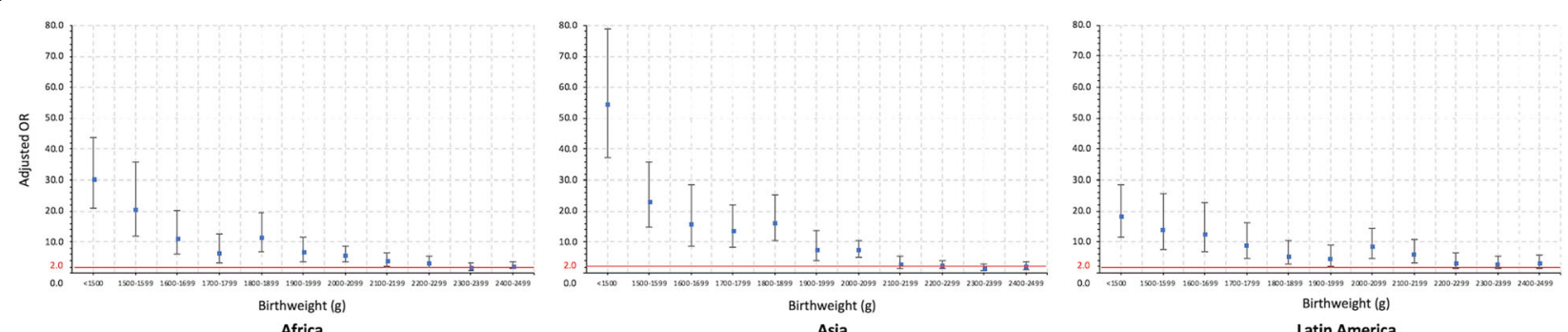

Fig. 3 Adjusted odds ratios with $95 \% \mathrm{Cl}$ of early neonatal mortality by birthweight in the three regions. Solid red line shows the adjusted OR 2.0 for clinical significance

consider these findings to be reliable in identify the clinically important outcome-based definition of low birthweight using ENM as a primary outcome.

The findings of this analysis are outcome-based criteria for which the definition of low birthweight was identified from the association model between birthweight and ENM adjusted for important confounding factors, maternal complications, gestational age at birth, mode of birth, fetal presentation and facility complexity index. The analyses were performed in the large, multicountry dataset of the WHO Global Survey [18]. Our findings based on the outcome-based approach done in the large database may be more appropriate than those based on statistical criteria [14, 30-34]. For example, Brimblecombe [30] suggested the classification of low birthweight based on birthweight distributional components. This study proposed two Gaussian distributions to describe birthweight - the primary distribution was composed of the majority of birthweights, whereas the secondary distribution was the minority of high-risk birthweights centered at the lower tail of the primary distribution. In 1980 Rooth proposed a definition of low birthweight based on a cut-off of weights less than two standard deviations below the local population mean, that better predicted risk for neonatal mortality [31]. Wilcox and Russell proposed an approach to explain association between birthweight and perinatal mortality. They suggested three parameters should define birthweight characteristics of a population: 1) mean and 2) standard deviation of the Gaussian distribution that included between 95 and $98 \%$ of term birthweight population, and 3) the proportion of all births in the residual distribution that mostly consisted of small preterm birth [32-34]. Recently, Njim et al. [14] conducted a twophased observational study to set a clinical cut-off point for LBW and to assess its incidence, predictors and complications in a sub-urban hospital in Cameroon. The authors found $2600 \mathrm{~g}$ was the cut-off at the 10th centile of birth weight for low birthweight. The cut-off point provided significant higher incidence of low birthweight (19\%) than that of the traditional cut-off of $2500 \mathrm{~g}$ (13.5\%). They also showed that newborns with birthweights between $2500 \mathrm{~g}$ and $2600 \mathrm{~g}$ had significant higher rates of complications than those with birthweights $>2600 \mathrm{~g}$ in the study population. Agbor et al. [15] also performed a study with a similar objective and method to Njim et al.'s paper in a rural sub-division in Cameroon. They assessed the statistical LBW cut-off at the 10th percentile of the observed birthweights distribution. They also made the comparison of neonatal adverse outcomes between LBW (birthweight <10th percentile) and heavier neonates (birthweight $\geq 10$ th percentile) in the study population for assessing the clinical significance. The authors reported the clinical cut-off point for LBW at $2700 \mathrm{~g}$ in the rural community in Cameroon. They found $6.1 \%$ of neonates had birthweights between $2500 \mathrm{~g}$ and $2700 \mathrm{~g}$, with higher stillbirth rate (about $3 \%, 5 / 163$ ) than those of heavier neonates $(<1 \%, 12 / 1553)$.

In our findings the odds of ENM clearly increased for every $100 \mathrm{~g}$ reduction of birth weight after $2200 \mathrm{~g}$. Malin et al. reported a similar finding in a systematic review a birthweight less than $1500 \mathrm{~g}$ had the highest odds of neonatal mortality (OR 48.6, 95\% CI 28.62, 82.53). Increasing the birthweight cut-off point to $2000 \mathrm{~g}, 2500 \mathrm{~g}$ or $2900 \mathrm{~g}$ gradually reduced the risk, but the summary estimates remained highly significant at each cut-off point [14]. This review did not report the risk of neonatal mortality by a narrower birthweight range (100 g each) as we did.

This study was a secondary analysis of the WHO Global Survey database conducted in 23 countries across Africa, Asia and Latin America. Trained personnel systematically collected the data. In the analyses, we controlled for important confounding factors of ENM such as maternal complications, gestational age at delivery, and mode of birth. However, the WHOGS database was primarily aimed at evaluating different modes of delivery and pregnancy outcomes, rather than to explore newborn birthweights specifically. The WHOGS was a facility-based survey, performed in large, secondary and tertiary facilities where caesarean section was available. Our findings might lead to over-representation of neonatal adverse outcomes and consequently might not reflect the situation in smaller facilities. There might be errors in birthweight data due to 
variations between facilities in the quality of birthweight measurement. For example, medical personnel might preferentially report birthweight values ending in a rounded number ( 0 or 5 ) which may affect the study findings. Our primary outcome focused only on early neonatal death occurring prior to discharge or day 7; information was not available on late neonatal or infant deaths. The crosssectional study design only permits us to evaluate associations rather than causation.

\section{Conclusions}

Our analysis suggests that the outcome-based definition of LBW of less than $2200 \mathrm{~g}$ may be used instead of the conventional less than $2500 \mathrm{~g}$ for assessing BW risk for early neonatal mortality. A regional specific definition of low birthweight $(<2200 \mathrm{~g}$ in Africa, $<2100 \mathrm{~g}$ in Asia and $<2200 \mathrm{~g}$ in Latin America) are quite similar and may be more appropriate for each region.

\section{Additional file}

Additional file 1: The percentage of early neonatal mortality by $100 \mathrm{~g}$ interval of birthweights. The rates of ENM among $100 \mathrm{~g}$ intervals of these birthweights are quite similar of around $0.5 \%$ in our analysed database. (PDF $185 \mathrm{~kb})$

\section{Abbreviations}

aORs: Adjusted odds ratios; Cls: Confidence intervals; ENM: Early neonatal mortality; FCl: Facility capacity index; g: Grams; kg: Kilograms; LBW: Low birthweight; LMICs: Low and middle income countries; ORs: Odds ratios; WHO: World Health Organization; WHOGS: WHO Global Survey

\section{Acknowledgements}

The authors wish to thank all members of the WHO Global Survey on Maternal and Perinatal Health (WHOGS, 2004-08), including regional and country coordinators, data collection coordinators, facility coordinators, data collectors, and all of the WHO offices and other staff of participating facilities who made the survey possible.

\section{Authors' contributions}

This study was conceptualized by ML and PL. ML and PL created initial draft of manuscript. SR and WC contribute to data analysis. ML, PL, SR, WC, JPS, JPV, RM and AMG authors interpreted results, read, participated in the final discussion and approved the submission.

\section{Funding}

WHO Global Survey on Maternal and Perinatal Health (WHOGS, 2004-08) was financially supported by the UNDP/UNFPA/WHO/World Bank Special Programme of Research, Development, and Research Training in Human Reproduction (HRP); WHO; United States Agency for International Development (USAID); Ministry of Health, Labour and Welfare of Japan; Ministry of Public Health of the People's Republic of China; and the Indian Council of Medical Research, India.

This secondary analysis study was financially supported by Thailand Research Fund (Distinguished Professor Award).

The sponsors had no role in data collection, analysis, or interpretation of the data, the writing of the report, or the decision to submit for publication.

\section{Availability of data and materials}

The datasets generated and/or analyzed during the current study are not publicly available due to they belonged to Department of Reproductive Health and Research, The World Health Organization but could be available from $\mathrm{WHO}$ on reasonable request.

\section{Ethics approval and consent to participate}

WHO Global Survey on Maternal and Perinatal Health (WHOGS, 2004-08) was approved by the research ethics review committee of World Health Organization and the relevant ethical clearance mechanisms in all countries. We received permission to use the data of this study from the Department of Reproductive Health and Research, WHO on the date January 14, 2014.

\section{Consent for publication}

Not applicable.

\section{Competing interests}

The authors declare that they have no competing interests.

\section{Author details}

'Department of Epidemiology and Biostatistics, Faculty of Public Health, Khon Kaen University, 123 Mittraphap Road, Nai-Muang, Muang District, Khon Kaen 40002, Thailand. 'Department of Obstetrics and Gynaecology, Faculty of Medicine, Khon Kaen University, Khon Kaen, Thailand. ${ }^{3}$ Bangkok Health Research Center 2 Soi Soonvijai 7, New Petchburi Rd., Huaykwang, Bangkok 10310, Thailand. ${ }^{4}$ Department of Social Medicine, Ribeirão Preto Medical School, University of São Paulo, Ribeirão Preto, SP, Brazil. ${ }^{5}$ UNDP . UNFPA • UNICEF - WHO • World Bank Special Programme of Research, Development and Research Training in Human Reproduction, Department of Reproductive Health and Research, World Health Organization, Geneva, Switzerland. ${ }^{6}$ Maternal and Child Health Program, Burnet Institute, 85 Commercial Road, Melbourne 3004, Australia. ${ }^{7}$ Department of Health Policy, National Center for Child Health and Development, Tokyo, Japan ${ }^{8}$ Department of Reproductive Health and Research World Health Organization, Avenue Appia 20, CH-1211 Geneva 27, Switzerland.

Received: 20 August 2018 Accepted: 20 May 2019

Published online: 27 May 2019

\section{References}

1. Wardlaw T, World Health Organization, UNICEF, editors. Low birthweight: country regional and global estimates. Geneva: New York: WHO; UNICEF; 2004

2. World Health Organization. ICD-10: international statistical classification of diseases and related health problems. 10th ed. Geneva: World Health Organisation; 1992.

3. Kramer MS. Determinants of low birth weight: methodological assessment and meta-analysis. Bull World Health Organ. 1987;65:663-737.

4. Chase HC. Infant mortality and weight at birth: 1960 United States birth cohort. Am J Public Health Nations Health. 1969:59:1618-28.

5. Ghosh S. Weight of all births and infant mortality. J Epidemiol Community Health. 1982:36:315.

6. Saugstad LF. Weight of all births and infant mortality. J Epidemiol Community Health. 1981:35:185-91.

7. Cutland CL, Lackritz EM, Mallett-Moore T, Bardaji A, Chandrasekaran R, Lahariya C, et al. Low birth weight: case definition \& guidelines for data collection, analysis, and presentation of maternal immunization safety data. Vaccine. 2017:35(48 Pt A):6492-500.

8. Zerbeto AB, Cortelo FM, Élio Filho BC. Association between gestational age and birth weight on the language development of Brazilian children: a systematic review. J Pediatr. 2015;91:326-32

9. Badshah S, Mason L, McKelvie K, Payne R, Lisboa PJ. Risk factors for low birthweight in the public-hospitals at Peshawar, NWFP-Pakistan. BMC Public Health. 2008;8:197.

10. Sicuri E, Bardají A, Sigauque B, Maixenchs M, Nhacolo A, Nhalungo D, et al. Costs associated with low birth weight in a rural area of southern Mozambique. PLoS One. 2011;6:e28744

11. Pathmanathan I, Liljestrand J, Martins JM, Rajapaksa LC, Lissner C, de Silva A, et al. Investing in maternal health: learning from Malaysia and Sri Lanka. Washington, DC: The World Bank; 2003.

12. Goldenberg RL, Hoffman HJ, Cliver SP, Cutter GR, Nelson KG, Copper RL. The influence of previous low birth weight on birth weight, gestational age, and anthropometric measurements in the current pregnancy. Obstet Gynecol. 1992:79:276-80.

13. Rode L, Hegaard HK, Kjærgaard H, Møller LF, Tabor A, Ottesen B. Association between maternal weight gain and birth weight. Obstet Gynecol. 2007;109: 1309-15. 
14. Njim T, Atashili J, Mbu R, Choukem SP. Low birth weight in a sub-urban area of Cameroon: an analysis of the clinical cut-off, incidence, predictors and complications. BMC Pregnancy Childbirth. 2015;15:1-8.

15. Agbor VN, Ditah C, Tochie JN, Njim T. Low birthweight in rural Cameroon: Q5 515 an analysis of a cut-off value. BMC Pregnancy Childbirth. 2018;18. https://doi.org/10.1186/s12884-018-1663-y.

16. Joseph KS, Fahey J, Platt RW, Liston RM, Lee SK, Sauve R, et al. An outcomebased approach for the creation of fetal growth standards: do singletons and twins need separate standards? Am J Epidemiol. 2009;169:616-24.

17. Ye J, Torloni MR, Ota E, Jayaratne K, Pileggi-Castro C, Ortiz-Panozo E, et al. Searching for the definition of macrosomia through an outcome-based approach in low- and middle-income countries: a secondary analysis of the WHO global survey in Africa, Asia and Latin America. BMC Pregnancy Childbirth. 2015;15:324

18. Lumbiganon P, Laopaiboon M, Gülmezoglu AM, Souza JP, Taneepanichskul $S$, Ruyan P, et al. Method of delivery and pregnancy outcomes in Asia: the WHO global survey on maternal and perinatal health 2007-08. Lancet. 2010; 375:490-9.

19. Shah A, Faundes A, Machoki M, Bataglia V, Amokrane F, Donner A, et al. Methodological considerations in implementing the WHO global survey for monitoring maternal and perinatal health. Bull World Health Organ. 2008;86: 126-31.

20. Souza JP, Cecatti JG, Faundes A, Morais SS, Villar J, Carroli G, et al. Maternal near miss and maternal death in the World Health Organization's 2005 global survey on maternal and perinatal health. Bull World Health Organ. 2010;88:113-9.

21. Maas CJM, Hox JJ. Sufficient sample sizes for multilevel modeling. Methodology. 2005;1:86-92.

22. Wilcox A, Skjaerven R, Buekens P, Kiely J. Birth weight and perinatal mortality. A comparison of the United States and Norway. JAMA. 1995;273: 709-11.

23. Graafmans WC, Richardus JH, Borsboom GJJM, Bakketeig L, Langhoff-Roos J, Bergsjø P, et al. Birth weight and perinatal mortality: a comparison of "optimal" birth weight in seven Western European countries. Epidemiology. 2002:13:569-74

24. Vangen S, Stoltenberg C, Skjaerven R, Magnus P, Harris JR, Stray-Pedersen B. The heavier the better? Birthweight and perinatal mortality in different ethnic groups. Int J Epidemiol. 2002;31:654-60

25. Habib NA, Dalveit AK, Mlay J, Oneko O, Shao J, Bergsjø P, et al. Birthweight and perinatal mortality among singletons and twins in North-Eastern Tanzania. Scand J Public Health. 2008;36:761-8.

26. Barrett JFR, Willan AR, Joseph KS. Planned cesarean or vaginal delivery for twin pregnancy. N Engl J Med. 2014;370:280.

27. Boulet SL, Alexander GR, Salihu HM, Kirby RS, Carlo WA. Fetal growth risk curves: defining levels of fetal growth restriction by neonatal death risk. Am J Obstet Gynecol. 2006;195:1571-7.

28. Mccluskey A, Lalkhen AG. Statistics IV: interpreting the results of statistical tests. Contin Educ Anaesthesia, Crit Care Pain. 2007:7:208-12.

29. Bates D, Maechler M, Bolker B, Walker SW. Fitting linear mixed-effects models using Ime4. J Stat Softw. 2015:67:1-48

30. Brimblecombe FS, Ashford JR. Significance of low birth weight in perinatal mortality. A study of variations within England and Wales. Br J Prev Soc Med. 1968:22:27-35.

31. Rooth G. Low birthweight revised. Lancet (London, England). 1980;1:639-41.

32. Wilcox AJ, Russell IT. Perinatal mortality: standardizing for birthweight is biased. Am J Epidemiol. 1983;1 18:857-64.

33. Wilcox AJ, Russell IT. Birthweight and perinatal mortality: III. Towards a new method of analysis. Int J Epidemiol. 1986;15:188-96.

34. Wilcox AJ, Russell IT. Birthweight and perinatal mortality: I. on the frequency distribution of birthweight. Int J Epidemiol. 1983;12:314-8.

\section{Publisher's Note}

Springer Nature remains neutral with regard to jurisdictional claims in published maps and institutional affiliations.

\section{Ready to submit your research? Choose BMC and benefit from:}

- fast, convenient online submission

- thorough peer review by experienced researchers in your field

- rapid publication on acceptance

- support for research data, including large and complex data types

- gold Open Access which fosters wider collaboration and increased citations

- maximum visibility for your research: over $100 \mathrm{M}$ website views per year

At $\mathrm{BMC}$, research is always in progress.

Learn more biomedcentral.com/submissions 